\title{
The Context of Current Content Analysis of Gender Roles: An Introduction to a Special Issue
}

\author{
Rena M. Rudy • Lucy Popova $\cdot$ Daniel G. Linz
}

Published online: 9 July 2010

(C) The Author(s) 2010. This article is published with open access at Springerlink.com

\begin{abstract}
The aim of this paper is to provide context for the quantitative content analyses of gender roles that are to be included in both parts of this special issue. First, a timeline of historical uses of the content analysis methodology is presented. Second, research objectives that frequently drive content analysis of gender roles are described; these include: to support feminist claims, to compare media with real life, to predict effects on audiences, and to detect effects of media producers on content. Third, previous content analyses published in Sex Roles and other gender-focused journals are reviewed and categorized in terms of medium, genre, time span, gender, and nationality. Finally, contributions of each of the articles in this special issue are outlined.
\end{abstract}

Keywords Content analysis · Gender roles $\cdot$ Feminism . Media effects $\cdot$ Special issue

\section{Introduction}

Content is ubiquitous. A perhaps inevitable result of humans' innate ability to symbolize is that text, images, music, and other symbols have come to inhabit almost every human activity, particularly in the developed world (see Bandura 1977). Attached to the human capacity to create symbols is a capacity to analyze symbols, and many scholars have embraced the task of content analysis in order to increase our understanding of our symbolized world. This analysis can take many forms, from narrative semiotics, functional pragmatics, objective hermeneutics, and related methodolo-

R. M. Rudy $(\bowtie) \cdot$ L. Popova $\cdot$ D. G. Linz

Department of Communication, University of California,

Santa Barbara, CA 93105-4020, USA

e-mail: rena@comm.ucsb.edu gies on the qualitative side of the epistemological spectrum (e.g., Titscher et al. 2000) to quantitative content analysis on the quantitative side (e.g., Neuendorf 2002). A natural focus of this analysis, whatever the methodology, is the symbols that (re)present our basic human traits, like sex, and the social constructions of our basic traits, like gender. Quantitative content analysis of gender roles is the focus of both this special issue and a second special issue scheduled to be published in Sex Roles later this year.

The primary aim of this paper is to provide context for the articles that follow. Historical context is provided through a review of a timeline of past content analysis research. Theoretical context is provided through a discussion of research objectives that typically drive the analysis of gender-roles content. Quantitative context is provided through a description and classification of content analysis articles published in gender-focused journals, and in particular, in Sex Roles. Immediate context is provided through an overview of some of the innovations and contributions of the specific articles in this special issue. The discussion proceeds from most general to most specific, from information about content analysis, to information about content analysis of gender roles, to information about content analysis of gender roles in Sex Roles, to information about content analysis of gender roles in this special issue of Sex Roles.

\section{History of Content Analysis}

Content analysis (a term henceforth used synonymously with "quantitative content analysis") is a research methodology in which specific message characteristics are systematically and objectively identified, with the purpose of making inferences about the contexts, causes, and effects 
of these messages (see Holsti 1969; Krippendorff 2004; Neuendorf 2002). In the broadest sense, people have examined the content of texts for millennia. However, content analysis as "the systematic, objective, quantitative analysis of message characteristics" (Neuendorf 2002, p. 1) emerged only around the beginning of the 20th century, following the development of mass media.

The early 20th century saw various calls to carry out large-scale content analysis of the printed press. In 1910, Weber proposed a wide-ranging content analysis of news media, and in 1912, Tenney recommended that newspaper content be continuously monitored for "social weather," just as the U.S. Weather Bureau monitors weather statistics (Krippendorff 2004). Neither enterprise was feasible at that time, but smaller content analysis projects began to materialize. In 1893, Speed produced a quantitative, longitudinal analysis of four New York newspapers published between 1881 and 1893, and similar studies were later conducted by Fenton $(1910,1911)$, Mathews (1910), Street (1909), and Wilcox (1900). Most of these studies used inches of newspaper columns as the dependent measure to determine the primary foci of "news" print outlets. During the following decades, Willey (1926) published a book about the content of weekly country newspapers, Woodward (1934) wrote Quantitative Newspaper Analysis as a Technique of Opinion Research, and Albig (1938) conducted the first content analysis of radio.

The world wars of the 20th century impacted not only the advancement of media technology, but also the development of content analysis. Some early content analysts focused on World War I; Lippmann and Merz (1920), for example, compared "facts" from daily coverage of the war's Russian front to the facts that became available after the war. But it was World War II, and the concomitant frenzy surrounding the feared impact of wartime propaganda, that established the type of content analysis that is still carried out today. Out of World War II propaganda studies came the first systematic presentation of content analysis, Berelson and Lazarsfeld's (1948) The Analysis of Communication Content, which was later published as Berelson's (1952) Content Analysis in Communication Research. An example of a study that led Berelson to his conclusions was one in which he and De Grazia (1947) analyzed German and Italian propaganda that was broadcast during the Second World War. They were able to correctly determine that the two nations were not cooperating in their propaganda efforts.

Another founder of modern content analysis was Lasswell. In the late 1940s, his book Language of Politics (Lasswell et al. 1949) featured discussions of validity, reliability, coding decisions, and other topics germane to content analysis methodology. Lasswell also conducted a "world attention survey," a large-scale content analysis of some speeches and of articles about the U.S. published in the French, German, British, Russian, and American elite press (see Lasswell et al. 1952).

Further development of content analysis was fostered by two interdisciplinary conferences: one in 1955, at the Allerton House of the University of Illinois (de Sola Pool 1959) and the other in 1966 at the University of Pennsylvania Annenberg School for Communication (Gerbner et al. 1969). Among many topics discussed at these conferences was the newly emerging technique of computer-assisted content analysis.

Eventually, the appeals for large-scale content analysis of mass media made at the beginning of the 20th century came to fruition. In 1969, Gerbner and colleagues began a "cultural indicators" project (see Gerbner 1969). The project entailed the analysis of 1 week of fictional TV programming per year to examine trends in television portrayals of violence and of women, minorities, and the elderly. The project formally continued for nearly two decades, and similar research on cultural indicators continues today. Another large-scale content analysis project was the National Television Violence Study (NTVS). Starting in 1994, 10,000 hr of TV programming were coded over a three-year period to assess the amount and context of violence on television. More recent content analyses following in the tradition of NTVS have embraced its large scale. The Sex on TV project (most recently, Kunkel et al. 2005), for instance, applied similar methodology to four large-scale biennial analyses of sexual content on entertainment television, and the ambitious aims of the current Annenberg-Robert Wood Johnson Coding of Health and Media Project (CHAMP) include analyzing the content of multiple media (film, television, music, and the Internet) over the course of multiple years (as many as 60 , depending on the medium) (Hardy et al. 2008; "Media Health Coding," 2010).

In recent years, the number of content analyses published in various disciplines has increased exponentially (e.g., Riffe and Freitag 1997). Content analysis is exercised in such diverse fields as communication, political science, psychology, literature, and business. For example, in clinical psychology, patients' writing has been analyzed in order to identify the patients' pathologies and personalities (e.g., Allport 1965); in history and literature, content analysis has aided researchers in determining authorship of such works as Imitation of Christ (Yule 1944) and some of the Federalist Papers (Mosteller and Wallace 1964); and in music, content analysis has been employed to assess the originality of works of classical composers (Simonton 1994).

\section{Research Objectives for Gender-Related Content Analysis}

In the field of gender studies, the yield of content analyses has been especially abundant (see Neuendorf 2002). 
Portrayals of men's and women's roles, relationships, conflict-resolution strategies, ages, races, languages, goals and aspirations, sizes and weights, and many other characteristics have all been examined through content analysis. In fact, so many content analyses related to gender roles have been published that some authors lament that "journals seem glutted with gender studies of contents" (Jolliffe 1993, p. 93). Nor is that scholars' only lament. Various scholars have complained that many content analyses seem to lack any theoretical grounding, and have cautioned that content analysis is just a methodology and not a value in itself (e.g., "Content is not the whole issue; rather, the issue is what can be legitimately inferred from available texts," Krippendorff 2004, p. 10). A content analysis is only as valuable as the rationale behind it.

The historical trajectory of content analysis as a research methodology has co-occurred with the historical trajectory of scholarly interest in gender equality. Surveying both trajectories together reveals popular types of theoretical and practical rationales for conducting gender-related content analysis.

\section{To Support Feminist Claims}

The historical roots of the analysis of gender-related content lie in the practical agendas of a sociopolitical movement, and they illustrate one of the primary objectives for analyzing content involving gender roles. One of the driving forces behind gender-role content analysis was the emergence of the modern women's movement beginning in the 1950s (Strinati 2004) and the attention this movement began to pay to media content in the early 1960s (Rakow 1986). Stern (1999) recounted, "The major task of early feminist researchers across disciplines was to document the assertion that images of women in Western culture have generally been created from the male perspective" (p. 2). In some early feminist writings (e.g., de Beauvoir 1949; Firestone 1971; Lakoff 1975; Welter 1966) this documentation consisted of the critical examination of content, drawing on individual observations and anecdotes. This method, however, did not allow for generalizations. Therefore, it became necessary "to examine the criticisms made by feminist writers in light of systematic content analysis" (Dominick and Rauch 1972, p. 30). In one such systematic content analysis, King (2008) framed a study of police action films by the need to assess the "context in which women struggle against the constraints of a maledominated industry" (p. 240), and in another, Len-Rios et al. (2005) analyzed two U.S. newspapers to determine whether or not they "unwittingly contribute to public consent of masculine cultural hegemony" (p. 153).

Some of the earliest gender-roles content analyses focused on comic strips (Saenger 1955; Spiegelman et al.
1953). Rather than limiting their studies by merely counting numbers of males and females (and, e.g., finding that comic strips featured twice as many men as women; Spiegelman et al. 1953), the researchers of these cartoon studies analyzed more complex latent variables, such as the aspirations, emotionality, intelligence, and relationships of various characters. They observed that men in comic strips were primarily concerned with achieving power and justice by violent or industrious means and that women in comic strips sought more passive goals of romantic love and domestic comfort through their personal charm (Spiegelman et al. 1953). Among other findings, the comic-strip studies demonstrated that portrayals of men and women differed depending on the characters' marital status. Single men mastered all situations, were aggressive, and were drawn bigger than were females, yet once they got married, men were portrayed as less aggressive, more powerless, and more irrational, and they were even visually shrunk until they were smaller than were their wives (Saenger 1955).

Goffman's (1979) book Gender advertisements is a landmark publication in the realm of the representation of women in advertisements, largely due to Goffman's classification system of implicit and explicit gender roles. His sample of over 500 photographic advertisements portrayed women as subordinates to men and portrayed men as overlords who treat women as children rather than equals.

Systematic content analyses have generally supported the criticisms of feminist writers; they have consistently found that men are more likely than are women to appear in almost all media texts, and that men and women are often shown in roles that are traditional and stereotyped (e.g., Courtney and Whipple 1983; Tuchman et al. 1978). These findings appeared in the earliest content analyses of gender roles and continue to appear today. The history of the relationship of the women's movement to content analysis illustrates a primary research objective behind genderrelated content analyses, then: to find support for feminist claims that "popular culture and the mass media have dealt with women and their representations in an unfair, unjust and exploitative manner" (Strinati 2004, p. 160).

This is only one potential motivation for producing gender-related content analysis. Other research objectives can be roughly classified into three additional groups, for a total of four research objectives (which can also be considered goals, motivations, or rationales):

(1) to support feminist claims about gender-based inequities,

(2) to examine the equivalence (or lack thereof) between reality and its media representations,

(3) to provide a basis for theory and research into effects that messages have on audiences, and

(4) to provide a basis for theory and research into effects that message producers have on message content. 
The categories may overlap, as in the hypothetical case of a feminist who, out of concern that media representations may influence young girls' self-image, investigates gender-based inequities in media portrayals that are different from real life. However, even if research objectives do overlap, genderfocused content analysts themselves often originate from only one of three perspectives or traditions, corresponding to the first, third, and fourth research objectives: feminism, media effects, and media production. The four categories may not be exhaustive or mutually exclusive, but they nevertheless provide a useful framework for discussing gender-based content analyses.

\section{To Compare Media with Reality}

Overlaps between the first two research objectives were evident in feminists' earliest gender-related content analyses, which were partially motivated by the goal to find correspondence (or lack thereof) between social reality and its media representations; "A central question is whether the sex role presentations are reasonable and realistic or overly restrictive and negative" (Macklin and Kolbe 1984, p. 34). Even though some feminists may challenge the assumption that "there could be some veridical account of social life in the media, that it is possible for the media to be a mirror of society rather than always a construction of some kind of reality" (Rakow 1986, p. 18), few would argue with the claim that the societal mirror of media presents images that vary in their level of distortion. Some content analysts have proposed that the extent of this distortion is minimal; Geise (1979), for instance, concluded that the goals and roles of women depicted in nonfictional content in women's magazines were reflexive of changes occurring in American society between 1955 and 1975. However, a substantial body of research (e.g., Busby 1975; Fouts and Burggraf 2000; Harwood and Anderson 2002; Herrett-Skjellum and Allen 1995) has concluded that media often fail to accurately reflect the real-world statistical distribution of sexes, roles, races, and occupations, and that media otherwise portray women stereotypically rather than realistically. Researchers with a media/reality-comparison objective investigate these unrealistic media portrayals, often comparing older media content with newer media content to gauge the extent and direction of change in portrayals of women.

\section{To Predict Effects of Media Content on Audiences}

Some scholars believe that research whose sole goal is to describe unequal portrayals and/or compare media content with the real world is limited. Jolliffe (1993), for instance, asserted that good content analyses "go beyond the snapshot of content to suggest how or why the content exists or what its effects are on public attitudes or behaviors" (p. 93). Many gender-focused content analysts combine their results with knowledge about media influence in order to predict likely effects of the content that they analyzed. This motivation was expressed in one of the earliest content analyses of gender roles in the media: "The study of the content of the mass media of communications is often predicated on the assumption that they exert influence on their public" (Saenger 1955, p. 195). Goffman (1979) echoed this thought, asserting that gender role portrayals both reflect social reality and shape social reality by influencing audience conceptions of what is proper, desirable, and normal.

The notion that media content has effects can not only serve to motivate researchers to study content, but it can also serve to direct investigations of effects. In the 1970's, Busby (1975) noted, "before effects studies and discussions of media content could be engaged in with some perspective, measurements were needed of the exact nature of sex roles in the various media" (p. 108). Since then, few researchers have utilized content analyses to directly and simultaneously link content with effects. Among those few are Collins et al. (2003), who conducted telephone interviews with 1,792 adolescents at the beginning and end of a year and analyzed the content of the television programs broadcast during that year. Because the researchers were able to determine the precise content viewed by the teenagers, they were able to directly link exposure to specific types of content with specific outcomes. Even though studies involving multiple research methodologies require substantial resources, combining content analyses with experiments or survey research can provide multiplicative benefits.

The two media-effects theories that are likely the most frequently cited as theoretical rationales for content analyses are social cognitive theory (e.g., Bandura 1977) and cultivation theory (e.g., Gerbner and Gross 1976). Social cognitive theory (which was first described under the name "social learning theory") suggests that people learn from media just as they learn from real-world models of behavior; therefore, factors that increase real-world social learning - such as repetition of particular types of messages and such as congruence between gender of model and gender of learner - can also influence learning from media (see Bandura 1986). Cultivation theory suggests that extensive media exposure leads audience members to adopt media reality as their own, and these altered conceptions of reality can in turn influence behavior (see Gerbner and Gross 1976). Because both theories propose mechanisms whereby media content constructs social reality, they lend themselves naturally to the explanatory framework of content analyses that investigate the social construction of gender. 


\section{To Detect Effects of Media Producers on Media Content}

Media producers, as members of a mediated society, have likely been influenced by media content just as other audience members have, but they possess the unique ability to shape further content to reflect their own views and the views of society, and thereby to cyclically shape further effects. A fourth research objective of content analysis, then, is to detect the influence of media producers on their content. Whereas content analysts with the media-effects motivation tend to focus on audience members, asking, "What does this content have to say about its potential effects?", content analysts with the media-production motivation tend to focus on content producers, asking, "What does this content have to say about the people who produced it?". The former motivation is largely a psychological one, while the latter is largely sociological.

An example of researchers with a media-producer research objective are Rusu and Bencic (2007), who analyzed 400 online personal advertisements by Romanian men and women and found that, consistent with the evolutionary psychology theory of parental investment (Trivers 1972), men were more likely than were women to offer resources and to seek attributes of health and fertility in their partners, while women were more focused on older partners and their wealth. Gender-related research motivated by a media-producer objective more typically compares content produced by one gender to content produced by the other. Armstrong (2004), for instance, examined patterns of use of male and female sources by male and female journalists. Other prominent examples of this objective can be found in cross-cultural content analyses in which similar content produced in different cultures or countries is compared. Gilly (1988), for instance, made conclusions about differences in genderrole beliefs across three countries when she found that Mexican advertisements reflected more traditional gender roles than did those found in the U.S. and Australia, and that representations of men and women were most equitable in Australia. Knopp (1980) compared illustrations in school readers from East Germany with those from West Germany and attributed gender-bias differences between the two countries to the countries' divergent economic systems (capitalism versus socialism).

Scholars who adopt a media-production research objective hold any of several perspectives on media content producers. One is that the attitudes of content producers reflect greater sociological movements, and therefore, media content is one index of the views that are widespread within a society. Another is that media producers reflect their own humanity in the content they produce, and therefore, media content can reveal sex differences and other facets of human nature. A third is that the output of media content producers reflects decision making within their particular institutions (journalism, entertainment, advertisement, etc.), and therefore, shedding light on media content can shed light on the inner workings of media institutions. A fourth perspective is that media producers wield enormous power, and detecting entrenched viewpoints and prejudices is the first step to eliminating unwanted viewpoints and prejudices in media content and in society.

\section{Overview of Gender-Related Content Analysis in Sex Roles}

As one of the premiere socioscientific journals of genderrelated research, Sex Roles: A Journal of Research includes a wide variety of perspectives and research objectives. In the absence of journals focusing narrowly on quantitative content analysis of gender roles, researchers have largely relied on gender-focused publications to publish their gender-related content analyses. In order to form a rough overview of such studies, we reviewed articles in genderfocused journals. (Because we sought only a preliminary, rough meta-content-analysis, and because we primarily focused on manifest content, we elected not to conduct a formal quantitative content analysis in the sense of creating a code book and employing multiple coders; as a result, the figures that follow should be considered preliminary.) In November of 2009, the following command search was used to filter the PSYCInfo database: KW = (content within 3 anal $\left.^{*}\right)$ and $\mathrm{JN}=(($ feminis* or wom* or men* or gender* or sex*) or (affilia or camera obscura or nwsa or signs)) and not $J \mathrm{~N}=$ (mental or menopause). These search terms were meant to capture journals in the database that have a gender element in their title, as well as some wellknown journals whose titles are more abstract but nevertheless focus on gender roles or women's issues. This search strategy limits this overview to journals in the PSYCInfo database and to journals that focus on gender rather than media, and it thereby excludes many articles about qualitative studies, articles in journals with low circulation, and articles by media scholars that are published in media journals (though when such media-journal articles do address gender, they tend to have gender as only a minor focus). Nevertheless, the sample does provide a rough gauge of the number of gender-focused journals that publish quantitative content analyses, and it does offer some insight into the types of content analyses that interest gender scholars.

The search yielded 393 articles in 64 different publications. After eliminating journals that are irrelevant because they focus on sexual behavior rather than gender roles, only 4 of those 64 journals contained 15 or more relevant articles. In order of number of search results, the most 
prominent journals were Sex Roles (133 articles), Psychology of Women Quarterly (28 articles), Health Care for Women International (27 articles), and Women \& Health (15 articles). (Journals with between 5 and 15 search results each included Gender and Society; Feminism \& Psychology; Violence Against Women; Journal of Feminist Family Therapy; Men and Masculinities; Scholarship for the Care of Women, Childbearing Families, \& Newborns; Women's Studies International Forum; Sexualities; and The Journal of Men's Studies.) Not all of those search results pointed to quantitative content analyses, however. Of the 204 relevant articles in the top 4 journals, 149 were quantitative content analyses, as opposed to qualitative thematic analyses, narrative analyses, or surveys. The ratio of quantitative to total articles was 126:133 for Sex Roles, 11:28 for Psychology of Women Quarterly, 1:27 for Health Care for Women International, and 11:15 for Women \& Health. A conclusion that follows from this analysis is that Sex Roles is the gender-focused journal that is the overwhelming frontrunner in publishing quantitative content analyses.

In order to investigate Sex Roles in greater detail, additional searches were conducted to identify as many of the journal's content analysis articles as possible. In addition to the 126 quantitative content analyses located in the initial search, a further 10 Sex Roles articles were found in searches for computer-assisted content analyses. In addition, reference lists of the most recently published content analysis articles were examined, revealing an additional 4 articles that did not appear in the initial searches. The selected studies were reviewed to answer questions about the number and types of articles that were published, as well as the elements of content that were analyzed.

\section{Number of Articles}

Sex Roles: A Journal of Research is an interdisciplinary journal that debuted in 1975. Its first content analysis appeared in 1978 and since then not a year has passed (with the exception of 1983) without the appearance of another content analysis in its pages. Overall, 140 content analysis articles have been published in this journal (as of November 2009), at a rate of over 4 per year, with a range of 1 to 9 per year.

Type of Medium and Genre

Some Sex Roles content analyses have investigated nonmedia content, including open-ended questions, interviews, personal narratives, dream diaries, conversations between children and parents, letters of recommendation, phone calls to public servants, and gossip in student lounges. However, mass media content has dominated the studies ( $81 \%$ of the 140 articles). Of the mass media, television has been the most popular medium among content analysts (42 articles, or $37 \%$ of mass media articles), followed by magazines (31 articles, or $27 \%$ ), books (15 articles, or $13 \%$ ), and newspapers (10 articles, or $9 \%)$; combined, printed matter constitutes the subject of almost half of the articles (see Table 1). Few studies have investigated the old media of radio ( 2 articles) and film ( 3 articles) and few have investigated the newest media ( 2 articles examined video games, 2 articles examined software, 1 article examined online news, and 1 article examined online personal ads).

Across all media content analyses, entertainment content accounted for $44 \%$ of analyses, and advertising content composed $38 \%$ of all articles. Among combinations of genre and content, the greatest number of studies (22) was dedicated to television advertisements, followed by television entertainment (18), magazine advertisements (13), and magazine entertainment (12). Only four studies investigated gender roles in the news (magazines, newspapers, the Internet, and television were represented by one study each).

Table 1 illustrates the combinations of medium and genre that have been frequently and infrequently examined. While the un(der)populated cells may illuminate areas in need of research, a lack of research alone does not justify expending the resources necessary to conduct a content
Table 1 Distribution of content analysis studies published in Sex Roles: A Journal of Research, 1978-2009, by medium and genre.

\begin{tabular}{llllllll}
\hline Medium & All content & Entertainment & Advertisement & Education & News & Other & Total \\
\hline TV & 1 & 18 & 22 & 0 & 1 & 0 & 42 \\
Magazines & 3 & 12 & 13 & 1 & 1 & 1 & 31 \\
Books & 0 & 9 & 0 & 6 & 0 & 0 & 15 \\
Newspapers & 0 & 3 & 6 & 0 & 1 & 0 & 10 \\
Online Content & 0 & 2 & 0 & 0 & 0 & 3 & 5 \\
Films & 0 & 3 & 0 & 0 & 0 & 0 & 3 \\
Radio & 0 & 1 & 1 & 0 & 0 & 0 & 2 \\
Software & 0 & 0 & 0 & 1 & 0 & 1 & 2 \\
Video games & 0 & 2 & 1 & 0 & 0 & 0 & 2 \\
Other & 0 & 0 & 43 & 0 & 1 & 0 & 2 \\
Total & 4 & 50 & & 8 & 4 & 5 & 114 \\
\hline
\end{tabular}


analysis. Identifying media that are unpopular according to Table 1 but popular among audiences may provide a valid justification, however. Such media do exist; the representation of different media in gender-related content analysis does not reflect real-world exposure to those media. The most recent Simmons New Media Study (2009) determined that, on average, Americans spend $3 \mathrm{hr}$ per day watching television, $2.4 \mathrm{hr}$ per day using the Internet via home computer, $1.7 \mathrm{hr}$ per day listening to the radio, and $1.5 \mathrm{hr}$ per day reading books. Media use figures are similar among American youth; the Kaiser Family Foundation Generation M2 study (Rideout et al. 2010) determined that the most commonly used medium among Americans aged 8 to 18 years was television ( $4: 29$ per day), followed by music and other audio content (2:31), computers (1:29), video games $(1: 13)$, printed matter $(: 38)$, and films (:25).

While gender researchers' paramount interest in television mirrors American audiences', researchers' interest in printed matter does not; whereas almost half of the content analyses in Sex Roles featured printed text, only a small proportion of Americans' daily media exposure involves print media. Perhaps academics' natural predilection for words influences their research interests, or perhaps the practical benefits of analyzing static, purposefully crafted, small-scale, clear-cut printed content (see, e.g., Belknap and Leonard 1991) have outweighed the disadvantages of studying media that are relatively unpopular among real-world audiences.

Video games and the Internet have the opposite balance; they are popular among audiences but relatively unpopular among gender-focused content analysts. The paucity of content analyses of new media in Sex Roles could potentially be explained by two factors. First, content analyses involving gender and new media may be most frequently published in journals specializing in new-media research. Indeed, such journals do publish gender-related content analyses; for example, a study about presentations of information and communication technology on websites for girls was published in Journal of Computer-Mediated Communication (Raphael et al. 2006), a study about gender differences in adolescents' homepages appeared in Journal of Broadcasting \& Electronic Media (Stern 2004), and a study about gender differences in computer-mediated interactions was presented in Computers in Human Behavior (Sussman and Tyson 2000). A second potential reason for the dearth of analyses of online media content could be the methodological problems inherent in studying interactive media. Not only can new-media content change by the moment (as when a blogger publishes a new weblog entry) or by the person (as when a user selects a particular avatar), but its very existence can change by the moment (as when a web feed eliminates expired content) or by the person (as when a user selects filters on particular types of content). Interactive media content is unstable and customizable.
Constant development of new media and new content intensifies the need for researchers to carefully select the medium and genre that would most benefit from content analysis and to explicitly state the reasons for this selection. Depending on the researchers' motivation, researchers may see no advantage to studying popular media; for instance, if their primary aim is to investigate media content producers' views about gender, then the popularity of a medium may be reduced to irrelevance.

\section{Time Span}

The number of content analysis articles in Sex Roles has increased each decade, from 32 starting from the journal's inception through the end of the 1980s to 51 in the 1990s to 57 so far in the 2000s. Most of these studies have provided only a "snapshot" cross-section of content. Among studies that have analyzed mass media content, only $20 \%$ (23 articles) have examined the content over time and an additional $7 \%$ ( 8 articles) have compared new findings to the findings of previous studies of similar content. None of the studies that analyzed intrapersonal or interpersonal content took a longitudinal approach.

\section{Subject Gender}

Of 114 mass media studies, the majority (95 studies, or $83 \%$ ) investigated representations of both men and women. Sixteen studies (14\%) focused entirely on women, and only three studies (3\%) focused entirely on men. The scarcity of content analysis research exclusive to men could be detrimental; some researchers have found evidence that while media coverage of women has neither substantially improved nor worsened in the last hundred years, coverage of men has become "radically worse" (Jolliffe 1993, p. 95).

\section{Nationality}

The U.S. was the exclusive focus of 108 (77\%) studies. Six studies (4\%) examined Canadian content, and Canada was followed in prominence by Israel and Spain, with 3 studies each, and Australia and Germany, with 2 studies each. Only one study originated in Africa (Kenya) and none investigated Central or South America. A total of seven studies analyzed and compared content from multiple countries and at least five other studies focused on a single country (usually other than the U.S.) and compared the findings of that country to results of studies conducted in other countries. The incidence of cross-cultural studies appears to be increasing; no cross-cultural content analysis was published in Sex Roles in the 1970s and 1980s, and all studies that focused on one country but compared that country with others were published in the 1990s. Studies 
that compared content from multiple countries at once span the publication period of Sex Roles, but the majority have appeared in the 2000 s.

\section{The Present Special Issue}

The historical context provided by content analysis in general, gender-related content analysis more specifically, and genderrelated content analysis in Sex Roles even more specifically has doubtless influenced the entrants into this special issue. In some respects, the studies included in the current special issue are typical content analyses. For instance, the medium most commonly featured is television (Desmond and Danilewicz 2010; Finger et al. 2010; Hether and Murphy 2010; Kahlenberg and Hein 2010; Zhang et al. 2010), and the genre most commonly featured is entertainment (all studies but those by Desmond and Danilewicz 2010, who analyzed news programs, and Kahlenberg and Hein 2010, who analyzed advertisements). Consistent with the majority of Sex Roles' previous content analyses, the majority of studies in this issue investigated both males and females (all studies but those by Gilpatric 2010; Neuendorf et al. 2010; and Zhang et al. 2010; all of whom studied females exclusively).

However, the papers included in the current special issue differ from the norm in several important respects. First of all, half of the articles investigated media whose content is not typically analyzed-video games (Downs and Smith 2010) and films (Gilpatric 2010; Neuendorf et al. 2010; Smith et al. 2010; Welsh 2010)_and the medium-genre combination with the highest incidence in this special issue is an uncommon one: entertainment films. One group of authors included in this special issue noted that film portrayals are "a body of media content that is often overlooked by content analysts but holds great potential for media effects due to its pervasive and enduring presence in Western culture" (Neuendorf et al. 2010, this issue). Their study of entertainment films incorporated an entire census of films (the James Bond film series) that encompassed an unusually long time period (40 years). Perhaps the increasing availability of old and obscure films through online DVD-rental companies such as Netflix has enabled researchers to investigate combinations of films that would have been difficult or impossible to screen a decade ago.

All of the studies in this special issue that focused on the medium of film collected samples over a broad time range and statistically analyzed longitudinal differences in content. Finger et al.'s (2010) sample was the only nonfilm content in this special issue to statistically consider overtime differences, in this case differences in a prominent German television series across a 26-year span. Theirs is also the only study featuring content that is entirely nonAmerican, though Neuendorf et al.'s (2010) subject of interest (James Bond films) was largely UK-based, and other researchers (e.g., Desmond and Danilewicz 2010; Welsh 2010) considered intercultural issues in discussing results or previous literature.

A variety of media, genres, time periods, and nationalities is represented in this special issue, then, but each individual paper offers additional contributions to the field of gender-focused content analysis. Some of the contributions are theoretical (e.g., testing a theory's claims), some are methodological (e.g., applying novel coding schemes), and some are practical (e.g., informing consumers about media content on the market).

\section{Downs and Smith}

Downs and Smith (2010) adopted a media-effects perspective in their examination of portrayals of video-game characters. Their goal to predict effects of media content on audiences is typical in gender-related content analyses, as is their subgoal of comparing media portrayals with reality. However, several additional (implicit) goals were atypical-particularly, the goal to integrate awareness of both theoretical and practical concerns throughout the study. Some concepts of schema theory (e.g., Calvert and Huston 1987) were introduced in Downs and Smith's paper, but the theoretical perspective that drove their content analysis was social cognitive theory (see Bandura 1986). Downs and Smith noted that the primary cognitive processes outlined in social cognitive theory are particularly salient in video games, and they outlined elements of media content (such as attractiveness) that, according to the theory, can be expected to strengthen effects. These elements were coded as part of the content analysis. Downs's and Smith's sample selection, also, was based on social cognitive theory; they analyzed top-selling games because "theoretically, [the most frequently witnessed character images] are the images that the greatest number of gamers would be paying attention to and learning from" (this issue). Similarly, the selection of types of characters to analyze was based on their potential to be learned from; "this study chose to focus on primary and secondary characters only as these character are more likely to be focused on because of their importance to game play and game completion" (this issue). Social cognitive propositions were also reiterated in the discussion of results. The decisions made by Downs and Smith were clearly reasoned and well-founded in a particular theory-social cognitive theory directed choices of medium to study, content to code, sample to select, and characters to analyze - and as a result, the purpose of the study and its external relevance for media-effects researchers are evident.

The external relevance for laypeople is evident, as well. One of Downs and Smith's (2010) research questions 
engages an issue of interest to many groups of people, from video game players to parents, lawmakers, and the videogame industry: the validity of ESRB (Entertainment Software Review Board) ratings. Downs and Smith questioned not only the claims of the ESRB, but also the potential actions that parents and other video game purchasers might take to circumvent potential negative effects of undesirable portrayals of females in video games. In addition to determining that limiting video game purchases to G-rated video games does not protect consumers from certain types of sexist and sexualized content, Downs and Smith found that no particular brand of video-game console portrayed women as considerably less sexualized than any of the others (though sampled games from the Nintendo GameCube did contain more sexually revealing clothing than did games from the other gaming systems). According to Downs and Smith, parents cannot avoid female "hypersexuality" by simply purchasing a "less sexual" video-game system.

The authors addressed practical concerns by considering the implications of their research for researchers as well as laypeople, then, but they also addressed practical concerns statistically. First, they ensured that specific comparisons were valid; for a research question that involved an omnibus chi-square comparison among different video game ratings, they conducted statistical post hoc analyses in order to determine which specific ratings differed from which others (see Schwab 2008 for the benefits of this approach). Second, they set an a priori criterion for determining whether or not statistically significant results were also substantial enough to be important in the real world (see Kirk 1996, for the benefits of this approach); any gender difference in which the genders differed by less than $10 \%$ was considered practically nonsignificant, even if the difference was statistically significant. To an extent not usually found in gender-related content analyses, Downs and Smith (2010) ensured that their results were not only theoretically relevant but also practically relevant.

\section{Gilpatric}

Many, if not most, of the characters studied by Downs and Smith (2010) were the video-game equivalent of what Gilpatric (2010) has termed VFACs: Violent Female Action Characters. Gilpatric referenced a combination of the typical content-analysis research objectives: to support feminist claims, to compare media with reality, and to detect effects of media content. She cited feminist theorists, with their understanding that "female identities are informed by social codes rooted in popular culture," and she cited media-effects theorists Bandura (1986) and Gerbner (1998), with their understanding that media have the potential to influence young people's gender socialization.
Her study conducted comparisons of older media with newer media and of media portrayals with their real-life counterparts.

The approach that Gilpatric (2010) took to reach those goals, however-particularly with respect to her second research question - has not been frequently taken. Gilpatric sought to enhance the body of research amassed by interpretive feminist scholars, who have frequently analyzed VFACs in a qualitative manner, by essentially verifying their claims through quantitative means.

Quantitative content analysts generally seek to describe a distribution of content. A typical content analysis of media characters might result in a list of values of a variable (e.g., a list of marital-status options like "never married," "married," and "divorced") with percentages of characters who fall into each category. Each variable of interest would result in a different list, and a large number of variables and all of their lists could quickly become overwhelming.

Interpretive scholars generally analyze content with a more intuitive approach and create generalizations based on subjective impressions. Rather than (or, infrequently, in combination with) reporting results in numerical form, qualitative scholars frequently report results in the form of annotated lists of general themes (e.g., Tanner et al. 2003) or rules of representation (e.g., Bildtgard 2000). Bell (1992), for instance, reviewed title sequences of television shows frequently watched by older adults and determined that the typical elderly character is prominent, powerful, affluent, healthy, mentally active, admired, and asexual, and that "the essential values of the old patriarchy hold" (p.310). In other words, instead of describing a distribution of qualities among numerous people, interpretive scholars often describe a single person who represents the most frequently portrayed qualities.

Gilpatric (2010) combined qualitative and quantitative approaches to create "a profile or average type of female action character from the demographic data gathered" (this issue); this profile was created from quantitative data but takes a qualitative form. The profile Gilpatric created of the typical VFAC is of a woman who is "typically young, white, unmarried, highly educated, and often depicted in a male-dominated or high-status career" (this issue).

The benefit of this type of "profile" is that it corresponds to the schema theory concept of a "prototype." According to schema theory (e.g., Wicks 1992), people have knowledge structures ("schemas") for everything they experience. A person's default mental picture of a concept (e.g., "woman") is derived from exposure to numerous examples of that concept, and over time, the different attributes that the concept can have (e.g., tall, short, accomplished, subservient) are averaged out until the qualities in the default schema ("prototype") represent the most frequently experienced values (see Rosch 1978). For example, an 
African child's prototype for "woman" is likely to have dark skin if most of the women he meets are dark-skinned; similarly, a European child's prototype for "woman" is likely to be light-skinned. By this line of logic, the more a person is exposed to media representations of women, the more that person's schema for women comes to reflect media profiles of women. Therefore, discovering media profiles for women in various types of content could also mean discovering the qualities and actions that frequent media consumers associate with women - that is, the ways that women are expected to look, think, and behave.

Neuendorf, Gore, Dalessandro, Janstova, and Snyder-Suhy

Schemas can exist for narratives as well as for people and objects. Neuendorf et al. (2010) did not establish as a research objective the identification of a prototype for James Bond film narratives, but in their content analysis of James Bond films, they discovered "a relatively predictable diagesis..., one that includes consistent women's images and a linking of sexual behaviors with aggressive outcomes, including the mortality of Bond women" (this issue). Linking sexual behavior with aggression is one of the contributions of Neuendorf et al.'s (2010) content analysis.

Neuendorf et al. (2010) proposed that a dearth of research into the simultaneous combination of sex and violence in media portrayals of women, into the victimization of women in entertainment media generally, and into portrayals of women in the specific medium of film undermines the theoretical importance of these research endeavors. Because social cognitive theory (e.g., Bandura 1986) and excitation transfer theory (e.g., Zillmann 1998) posit important effects of these types of portrayals, and empirical research supports these theories, the authors' primary research objective was to examine content that might predict these effects. The authors noted that even though some research has demonstrated that the combination of sex and violence more powerfully affects people than does sex or violence alone, content analyses do not generally combine these content types, especially content analyses of genres other than horror and pornography.

Neither do content analyses usually predict the values of one variable based on the values of others, such as a character's violent victimhood based on her prior sexual activity. Social cognitive theory (e.g., Bandura 1986) suggests that audience members can vicariously learn norms and behavior from media models by vicariously experiencing the rewards and punishments that are meted out. Rather than only using content analysis methodology to report percentages, to compare some percentages to others, and/or to examine changes in percentages over time, Neuendorf et al. (2010) also used content analysis method- ology in combination with elements of correlational research to determine which characteristics and behavior of "Bond" women appear to instigate reward and punishment. Specifically, they investigated the extent to which various demographic and behavioral factors predicted (a) the reward of sexual activity; (b) the punishment of being a target of weapons; and (c) the ultimate punishment, death.

\section{Welsh}

Associating sexual activity with death using content analysis methods may be rare, but Welsh (2010), also, investigated this ultimate negative outcome in content spanning an even longer time period (49 years) than Neuendorf et al.'s (2010). The genre of choice for Welsh was "slasher" films. He noted that only one study (Cowan and O'Brien 1990) other than his "directly addressed the possibility of an interaction between gender, sexual activity, and violent victimization in the slasher film" (this issue), and that the results of that study were suspect for statistical reasons. Citing the continuing popularity of slasher films; arguments of feminists, legal scholars, and other critics of the genre; concepts from schema theory; and research demonstrating adverse effects of negative gender-role expectations; Welsh proposed (and ultimately found) that "good," virginal female characters would be rewarded for their self-restraint by survival, and that even when they did perish on film, their death scenes would be shorter than "bad" girls'.

\section{Smith, Pieper, Granados, and Choueiti}

Smith et al. (2010) investigated substantially different content: top-grossing G-rated films. They noted that even though films with a "G" rating as a group report higher worldwide revenues than do films of any other MPAA rating, and even though the young intended audience of most of these films may be especially susceptible to gender socialization messages in them, few studies have investigated gender representation in these films, and those that have have generally focused only on animated Disney films. In conducting their research on the little-researched content of G-rated films, Smith et al. took a media-effects perspective - they referenced schema theory (e.g., Martin and Halverson 1981) and social cognitive theory (Bandura 1986) - but they also referenced feminist critics, changes in content over time, and the lack of correspondence between media portrayals and the real world. As Downs and Smith (2010) did, Smith et al. (2010) relied on their theoretical perspective to guide their decisions about their sample (they selected top-grossing films to "ensure the sample featured films children are more likely to have in their media libraries and thus may have the most significant effect on 
gender-role schema development," this issue) and about their variables of interest (they elected to study demographic variables because studies of social cognitive theory and schema theory "have shown that children and young adults often are drawn to, like, and/or identify with media characters that they perceive as demographically similar to themselves," this issue). Also, just as Smith focused on practical matters in her study with Downs (Downs and Smith 2010), in this study (Smith et al. 2010), she and her coauthors established criteria for determining practical significance of their statistical results and outlined the practical implications of their results for parents, researchers, and media professionals.

Smith et al. (2010) reported an additional statistic that content analysts do not often report: unitizing reliability. Prior to coding, coders must decide what constitutes a coding unit. In many cases, this unit is obvious (for instance, in studies with "the newspaper page" as a unit of analysis, the unit is easily identifiable upon inspection). However, many units of analyses (e.g., a television scene, a film conversation) do not necessarily have discrete beginning and end points, and other units may depend on somewhat subjective criteria (e.g., that the unit of analysis be "the most prominent character"). Coders may therefore disagree about what exactly constitutes a particular unit of analysis and whether or not a particular media unit should be coded. (Problems with unitizing units of analysis may be similar to problems with unitizing units of observation and units of sampling; see, e.g., Neuendorf 2002.) Smith et al. (2010) acknowledged these potential problems with their study's "speaking character" unit of analysis; they realized that coders could potentially disagree about the number of such characters that appeared in their sample of films. In order to determine that their coders reached a satisfactory level of agreement about the number of characters to code, Smith et al. investigated whether or not the number of characters coded by each coder was within $20 \%$ of the mode (if not every time, then at least an acceptable percentage of the time, accounting for differences due to chance). Reporting unitizing reliability in content analysis reports offers readers assurance that unitizing was conducted systematically and consistently rather than haphazardly.

\section{Zhang, Dixon, and Conrad}

Like Smith et al. (2010), Zhang et al. (2010) concentrated on media content geared toward a particular audience. In the former study of G-rated films, it was children, and in the latter study of rap music videos, it was Black women. In their content analysis, Zhang et al. sought to overcome various limitations and omissions of previous research. The authors noted that previous analyses of body-image-related content focused on mainstream media directed at mainstream (i.e.,
White) audiences, despite the research evidence that (a) White American females differ from Black American females in self-esteem, conceptions of beauty, and vulnerability to messages about thin body ideals; and (b) different genres have a differential impact on viewers' self-conception. Presumably, the reason for this differential impact is that different genres portray different body types. The authors concluded that content analysis was needed to test this possibility. Zhang et al. chose an underresearched television genre - rap music videos - to test their hypotheses because rap music contains "an overwhelming number of Black women" (this issue), because it is viewed extensively by Black women, because many complaints have been raised about rap videos' sexualization of women, and because rap videos contain differing themes that may promote different perspectives about body image.

The last reason suggests that one of Zhang et al.'s (2010) research objectives was to predict media effects based on particular content. Indeed, they not only cited cultivation theory as a basis for their study (in addition to the theory of attributional ambiguity, Crocker and Major 1989), but they also tested an assumption of cultivation theory-namely, that television presents relatively homogeneous, "coherent" systems of messages (Gerbner et al. 2002). Contrary to this assumption, Zhang et al. found that even within a genre, various systems of messages are presented. In particular, music videos with a "sex" theme and/or a "materialism" theme portrayed women as significantly thinner than did music videos without these themes, and music videos with a "political awareness" theme portrayed women as significantly larger than did videos without this theme. "Consequently," the authors concluded, "these findings suggest that not only might genre-specific media viewing matter, but also exposure to specific content within a genre could have differential effects" (this issue).

Zhang et al. (2010) had a secondary goal that is shared among many content analysts: to compare the world portrayed by media with the unmediated world. Instead of making determinations solely on visual inspection of "media" and "real life" numbers, as many researchers do, however, the authors employed a statistical approach. Differences of proportion tests revealed that in American rap music videos, the percentages of Black women, White women, and women overall who were thin were significantly (and substantially) higher than these percentages are in the real United States.

Finger, Unz, and Schwab

Finger et al. (2010) questioned cultivation theory's minimizing of genre differences, as Zhang et al. (2010) did, but instead of testing the theory in their own content analysis, Finger et al. supplemented the theory with other explana- 
tory mechanisms, such as those found in the drench hypothesis, social role theory, and social cognitive theory. From the drench hypothesis (Greenberg 1988), Finger et al. appropriated the idea that not all content is equal; exposure to striking or noteworthy events can be more influential in producing important media effects than is mere frequency of exposure. From social role theory (Eagly 1987), they apparently drew their decision to hold "role" constant in tests of gender differences; according to Finger et al., social role theory posits that many real-world gender differences are the result of the different roles that men and women play in society rather than the result of biological differences. This notion is supported by social cognitive theory (Bandura 1986), which explains that people imitate models that are attractive and/or similar to themselves; as a result, slotting the different sexes into sex-typed roles in media can lead audience members to adopt sex-typed roles themselves and thereby perpetuate gender differences. Consequently, holding role constant by coding only characters with the same social role - in this case, the role of "chief inspector" in a popular German television crime drama - should provide a test of social role theory. Finding no gender differences would support the theory (if gender differences are evident across different roles but not within the same role, then role may account for the differences), but finding significant gender differences within the same (relatively high-status) role would lend support to the hypothesis that gender differences result from more than simple role differences. Finger et al. did indeed find gender differences within the role of chief inspector, suggesting that differences in social roles cannot account for differences in expressed emotion.

Challenging an established theory is not the only contribution of the content analysis by Finger et al. (2010); they also examined media from an understudied country. Germany, as the authors pointed out, is among the most egalitarian countries with respect to gender-role attitudes, whereas the U.S. (according to at least one study; see Williams and Best 1990) is midway between egalitarian and male-dominated, and countries from the Asian and African continents generally fall on the male-dominated end of the spectrum. In order to increase understanding of gender roles and the role of media content in perpetuating and challenging gender roles, increased attention on countries other than the U.S. is clearly warranted. The results of Finger et al.'s study demonstrate that even in an egalitarian country, gender differences in media persist.

An additional contribution of the content analysis by Finger et al. (2010) is methodological; the authors utilized an emotion coding system that is usually used in psychology and animation rather than in content analysis: EMFACS (Emotion Facial Action Coding System). The primary advantage of using this coding system is that it identifies emotion relatively objectively, through detection of small facial movements, rather than through an overall subjective impression. As a result, intercoder agreement among trained coders is usually high (Rosenberg and Ekman 1998). Other content analysts may also find this measurement system useful.

\section{Hether and Murphy}

Hether and Murphy (2010) studied entertainment television, as Finger et al. (2010) did, but Hether and Murphy's primary focus was on the educational potential of entertainment television, and of health-related entertainment storylines in particular. Hether and Murphy noted that entertainment-education programs "have the advantage of being able to engage viewers in a health issue for both a much longer duration and in greater depth than traditional health campaigns," and in addition, narrative formats "can circumvent counterarguing and sustain attention" (this issue). The practical, real-life, educational focus of this study is doubtless related to the authors' collaboration with Hollywood, Health \& Society, a program that encourages accurate depictions of health issues in entertainment media by providing health information to Hollywood writers and producers on an on-call basis. This focus is also doubtless related to the larger study of which this content analysis is a part; the Television Monitoring Project is a large-scale, multiyear analysis of health content in the most popular scripted television programs. Even though the overall research project of which this study is a part is large in scope, this particular content analysis of gendered health content is focused enough that variables of interest could be conceptually and operationally defined in a single, concise table (Hether and Murphy, Table 2).

As might be expected, given Hether and Murphy's (2010) focus on the educational value of media, the authors have integrated the potential impact of media into numerous aspects of their study. The theoretical basis of their study, social cognitive theory (e.g., Bandura 1986), highlights the importance of identification and perceived similarity between onscreen character and audience member with respect to intensifying effects. The authors therefore selected their study's variables and sample based on similarity, identification, and other factors relevant to the potential impact of health storylines. They also deliberately referenced real-world U.S. Census figures in order to compare their sample to real life.

Despite focusing on the education component of entertainment-education programming, Hether and Murphy (2010) did not lose sight of the entertainment component. Acknowledging that narrative entertainment programming is composed of individual storylines, Hether and Murphy used the storyline as one unit of analysis (in addition to the entire episode), and calculated intercoder reliability in 
unitizing storylines. In another methodological concession to narrative entertainment programming, this study's coders watched each program in its entirety before coding the program. This procedure was meant to minimize the potential of narrative entertainment to "sweep away" audiences (including content coders), as well as to give coders advance warning of particular types of content (including outcomes of medical ailments and treatments). Future research could investigate the influence of multiple viewings of source material on coding practice in content analysis.

\section{Desmond and Danilewicz}

Desmond and Danilewicz (2010), also, attended to coder issues when they ensured that coders in their content analysis were blind to the study's hypotheses. As did Hether and Murphy (2010), Desmond and Danilewicz based their study on social cognitive theory (Bandura 1986) and its emphasis on identification with behavioral models (in addition to cultivation theory and its emphasis on mainstreaming; see Gerbner et al. 1980). Also, just as Hether and Murphy focused on nonfictional (health) information in media, so also Desmond and Danilewicz focused on nonfictional (news) information. Hether and Murphy and Desmond and Danilewicz all interfaced with media professionals - the former pair of authors through the intermediary Hollywood, Health \& Society, and the latter pair of authors through direct contact.

Desmond and Danilewicz (2010) are noteworthy for the extent to which they drew on industry knowledge to develop their study. Their focus on local news, as opposed to the more typically researched national news, doubtless facilitated their gathering of industry information; the authors were able to conduct phone interviews with local personnel from each of the four major television networks. The knowledge they gleaned was instrumental in the authors' decision-making, from selecting November as the data collection period, to selecting $11 \mathrm{PM}$ as the newscast time-slot of interest, to eliminating FOX newscasts from consideration. One interview also aided in the interpretation of their results; Desmond and Danilewicz contended that gender-based inequities in assigning news stories are institutionalized rather than driven by individual reporters, and a local news director confirmed that he held the power to match news stories with reporters.

This institutionalization of gender differences was indeed a focus of Desmond and Danilewicz's (2010) content analysis. The authors shared the media-effectsdetection research goal of most content analysts included in this special issue, but unlike most of these content analysts, Desmond and Danilewicz primarily focused on a particular audience: those who might someday become media content producers. The authors suggested that effects of gendered news content might be most acute on young girls exposed to female models of news reporting and anchoring, because these youngsters might internalize any inequalities in the prevalence of female journalists or in the types of stories allotted to female reporters, and the girls might thereby become dissuaded from becoming journalists themselves. (Desmond and Danilewicz also suggested that inequalities can reduce job satisfaction among currently employed female journalists.) In other words, current media content can influence media content far into the future. Inequalities can also have short-term influence on news content; for instance, "if stereotypical topics are assigned by gender, rather than by expertise or talent, the quality of news suffers" (this issue).

A second goal of the Desmond and Danilewicz (2010) content analysis, then, was to detect effects of media producers on media content. Content analysis can provide evidence supporting claims about direct effects on audiences, but it can also provide evidence supporting claims about the beliefs and practices of content producers. To Desmond and Danilewicz, media content can potentially reveal entrenched double standards and demonstrate behind-the-scenes, institutional inequality.

\section{Kahlenberg and Hein}

Kahlenberg and Hein (2010) apparently share this view. Their research asked, "Do [Nickelodeon's] toy commercials reflect [Nickelodeon's] progressive corporate mindset, or the more narrow and traditional interests of the toy advertisers, who may eschew innovation in fear of market share erosion?" (this issue). One of Kahlenberg and Hein's research objectives, then, was to detect the influence of social actors on media content.

However, unlike many content analysts, who generally adhere to only one side of the media-reflect-society-versussociety-reflects-media debate, Kahlenberg and Hein took both positions; another of their research objectives was to address the influence of media content on social actors (and particularly, on children). One of the bases of their content analysis was the media-effects theory of cultivation (Gerbner et al. 2002); for instance, they chose to include repeated ads in their analysis because cultivation theory stresses the influence of repeated, cumulative television exposure. Another basis of their content analysis was cognitive development theories and the related concepts of schemas and socialization; because children's cognitive skills develop over time, Kahlenberg and Hein argued, media content directed at young audiences can be especially influential. To these scholars, media are important because children are cultural inventions and media are agents of culture, and toys are important because they usually are 
explicitly gender-defined and their economic significance is considerable. Kahlenberg and Hein highlighted the need for investigating the underresearched content category of toy advertising when they suggested, "With both media and toys acting as key modes of communicating societal messages, toy commercials are good examples of where these two areas intersect" (this issue).

\section{Conclusion}

This special issue is replete with investigations of underresearched media, genres, cultures, and time periods. Given the high salience of a person's gender in everyday life, and given people's typically high daily media exposure (e.g., Simmons New Media Study 2009), the value of rigorous studies of gender-related media content cannot be easily overestimated. While content analysis cannot directly answer questions about effects of content, nor can it determine motives of content producers, it dovetails into both lines of research. In addition, content analysis can serve to support or deny feminist claims, such as claims about the lack of correspondence between media portrayals and unmediated reality. The research methodology of content analysis may already have a long history, but much of its history is yet to be written. Research published in gender-focused journals such as Sex Roles suggests that additional content analysis is essential, and researchers are responding to this need; this research methodology is only picking up speed. Our hope is that this special issue might serve as a catalyst for even more-and even more innovative - content analyses of gender roles.

Open Access This article is distributed under the terms of the Creative Commons Attribution Noncommercial License which permits any noncommercial use, distribution, and reproduction in any medium, provided the original author(s) and source are credited.

\section{References}

Albig, W. (1938). The content of radio programs 1925-1935. Social Forces, 16, 338-349.

Allport, G. W. (1965). Letters from Jenny. New York: Harcourt Brace Jovanovich.

Armstrong, C. L. (2004). The influence on reporter gender on source selection in newspaper stories. Journalism and Mass Communication Quarterly, 81, 139-154.

Bandura, A. (1977). Social learning theory. Upper Saddle River: Prentice Hall.

Bandura, A. (1986). Social foundations of thought and action: A social cognitive theory. Englewood Cliffs: Prentice-Hall.

Belknap, P., \& Leonard, W. M. (1991). A conceptual replication and extension of Erving Goffman's study of gender advertisements. Sex Roles, 25, 103-118.
Bell, J. (1992). In search of a discourse on aging: The elderly on television. The Gerontologist, 32, 305-311.

Berelson, B. (1952). Content analysis in communications research. New York: Free Press.

Berelson, B., \& De Grazia, S. (1947). Detecting collaboration in propaganda. Public Opinion Quarterly, 11, 244-253.

Berelson, B., \& Lazarsfeld, P. F. (1948). The analysis of communication content. Oslo: Universitetets Studentkontor.

Bildtgard, T. (2000). The sexuality of elderly people on film-Visual limitations. Journal of Aging \& Identity, 5, 169-183.

Busby, L. J. (1975). Sex-role research on the mass media. The Journal of Communication, 25, 107-131.

Calvert, S. L., \& Huston, A. C. (1987). Television and children's gender schemata. In L. Liben \& M. Signorella (Eds.), New directions in child development: Vol. 38. Children's gender schemata: Origins and implications (pp. 75-88). San Francisco: Jossey Bass.

Collins, R. L., Elliott, M. N., Berry, S. H., Kanouse, D. E., \& Hunter, S. B. (2003). Entertainment television as a healthy sex educator: The impact of condom-efficacy information in an episode of friends. Pediatrics, 112, 1115-1121.

Courtney, A. E., \& Whipple, T. W. (1983). Sex stereotyping in advertising. Lexington: Lexington Books.

Cowan, G., \& O'Brien, M. (1990). Gender and survival vs. death in slasher films: A content analysis. Sex Roles, 25, 187-196.

Crocker, J., \& Major, B. (1989). Social stigma and self esteem: The selfprotective properties of stigma. Psychological Review, 96, 608-630.

De Beauvoir, S. (1949). The second sex (H. M. Parshley, Trans.). New York: Vintage Books.

de Sola Pool, I. (Ed.). (1959). Trends in content analysis: Papers. Champaign: University of Illinois Press.

Desmond, R., \& Danilewicz, A. (2010). Women are on, but not in, the news: Gender roles in local television news. Sex Roles, this issue.

Dominick, J. R., \& Rauch, G. E. (1972). The image of women in network TV commercials. Journal of Broadcasting \& Electronic Media, 16, 259-265.

Downs, E., \& Smith, S. L. (2010). Keeping abreast of hypersexuality: A video game character content analysis. Sex Roles, this issue.

Eagly, A. H. (1987). Sex differences in social behavior: A social role interpretation. Hillsdale: Erlbaum.

Fenton, F. (1910). The influence of newspaper presentations upon the growth of crime and other anti-social activity. The American Journal of Sociology, 16, 342-371.

Fenton, F. (1911). The influence of newspaper presentations upon the growth of crime and other anti-social activity (continued). The American Journal of Sociology, 16, 538-564.

Finger, J., Unz, D. C., \& Schwab, F. (2010). Crime scene investigation: The chief inspectors' display rules. Sex Roles, this issue.

Firestone, S. (1971). The dialectic of sex: The case for feminist revolution. New York: Bantam Books.

Fouts, G., \& Burggraf, K. (2000). Television situation comedies: Female weight, male negative comments, and audience reactions. Sex Roles, 42, 925-932.

Geise, L. A. (1979). The female role in middle class women's magazines from 1955 to 1976: A content analysis of nonfiction selections. Sex Roles, 5, 51-62.

Gerbner, G. (1969). Toward "cultural indicators": The analysis of mass mediated public message systems. AV Communication Review, 17, 137-148.

Gerbner, G. (1998). Cultivation analysis: An overview. Mass Communication \& Society, 1, 175-194.

Gerbner, G., \& Gross, L. (1976). Living with television: The violence profile. The Journal of Communication, 26, 172-199.

Gerbner, G., Holsti, O. R., Krippendorff, K., Paisley, W. J., \& Stone, P. J. (1969). The analysis of communication content. New York: Wiley. 
Gerbner, G., Gross, L., Morgan, M., \& Signorielli, N. (1980). The mainstreaming of America: Violence profile no. 11. The Journal of Communication, 30, 10-25.

Gerbner, G., Morgan, M., Gross, L., Signorielli, N., \& Shanahan, J. (2002). Growing up with television: Cultivation processes. In J. Bryant \& D. Zillmann (Eds.), Media effects: Advances in theory and research (2nd ed., pp. 43-67). Hillsdale: Erlbaum.

Gilly, M. C. (1988). Sex roles in advertising: A comparison of television advertisements in Australia, Mexico, and the United States. Journal of Marketing, 52, 75-85.

Gilpatric, K. (2010). Violent female action characters in contemporary American cinema. Sex Roles, this issue.

Goffman, E. (1979). Gender advertisements. New York: Harper Colophon Books.

Greenberg, B. (1988). Some uncommon television images and the drench hypothesis. In S. Oskamp (Ed.), Television as a social issue: Applied social psychology (Annual 8) (pp. 88-102). Newberry Park: Sage.

Hardy, B., Jamieson, P. E., Romer, D., \& Jamieson, K. H. (2008). The Annenberg coding of health and media project: Rationale and plans. Retrieved from http://www.youthmediarisk.org/Down loads/MediaCodingReview_20081201.pdf.

Harwood, J., \& Anderson, K. (2002). The presence and portrayal of social groups on prime-time television. Communication Reports, 15(2), 81-98.

Herrett-Skjellum, J., \& Allen, M. (1995). Television programming and sex stereotyping: A meta-analysis. Communication Yearbook, 19, $157-185$

Hether, H. J., \& Murphy, S. T. (2010). Sex roles in health storylines on prime time television: A content analysis. Sex Roles, this issue.

Holsti, O. R. (1969). Content analysis for the social sciences and humanities. Reading: Addison-Wesley.

Jolliffe, L. (1993). Yes! More content analysis. Newspaper Research Journal, 14, 93-97.

Kahlenberg, S. G., \& Hein, M. M. (2010). Progression on Nickelodeon? Gender-role stereotypes in toy commercials. Sex Roles, this issue.

King, N. (2008). Generic womanhood: Gendered depictions in cop action cinema. Gender \& Society, 22, 238-260.

Kirk, R. E. (1996). Practical significance: A concept whose time has come. Educational and Psychological Measurement, 56, 746759.

Knopp, S. (1980). Sexism in the pictures of children's readers: East and West Germany compared. Sex Roles, 6, 189-205.

Krippendorff, K. (2004). Content analysis: An introduction to its methodology (2nd ed.). Thousand Oaks: Sage.

Kunkel, D., Eyal, K., Finnerty, K., Biely, E., \& Donnerstein, E. (2005). Sex on TV 4. Menlo Park: Henry J. Kaiser Family Foundation.

Lakoff, R. (1975). Language and woman's place. New York: Harper \& Row.

Lasswell, H. D., Leites, N., Fadner, R., Goldsen, J. M., Grey, A., Janis, I. L., et al. (1949). Language of politics: Studies in quantitative semantics. New York, NY: George W. Stewart.

Lasswell, H. D., Lerner, D., \& de Sola Pool, I. (1952). The comparative study of symbols: An introduction. Palo Alto: Stanford University Press.

Len-Rios, M. E., Rodgers, S., Thorson, E., \& Yoon, D. (2005). Representation of women in news and photos: Comparing content to perceptions. The Journal of Communication, 55, $152-168$.

Lippmann, W., \& Merz, C. (1920). A test of the news [Special supplement]. The New Republic, 23(296), 1-42.

Macklin, M. C., \& Kolbe, R. H. (1984). Sex role stereotyping in children's advertising: Current and past trends. Journal of Advertising, 13, 34-42.
Martin, C. L., \& Halverson, C. F. (1981). A schematic processing model of sex typing and stereotyping in children. Child Development, 52, 1119-1134.

Mathews, B. (1910). A study of a New York daily. Independent, 68, $82-86$.

Media health coding: Capturing changes over time. (2010). Retrieved from http://www.youthmediarisk.org.

Mosteller, F., \& Wallace, D. L. (1964). Inference and disputed authorship: The Federalist papers. Series in behavioral science: Quantitative methods. Massachusetts: Addison-Wesley.

Neuendorf, K. A. (2002). The content analysis guidebook. Thousand Oaks: Sage.

Neuendorf, K. A., Gore, T. D., Dalessandro, A., Janstova, P., \& Snyder-Suhy, S. (2010). Shaken and stirred: A content analysis of women's portrayals in James Bond films. Sex Roles, this issue.

Rakow, L. F. (1986). Rethinking gender research in communication. The Journal of Communication, 36, 11-26.

Raphael, C., Bachen, C., Lynn, K. M., Baldwin-Philippi, J., \& McKee, K. A. (2006). Portrayals of information and communication technology on World Wide Web sites for girls. Journal of Computer Mediated Communication, 11, 771-801.

Rideout, V. J., Foehr, U. G., \& Roberts, D. F. (2010). Generation M2: Media in the lives of 8- to 18-year-olds. Menlo Park: Henry J. Kaiser Family Foundation.

Riffe, D., \& Freitag, A. (1997). A content analysis of content analyses: Twenty-five years of Journalism Quarterly. Journalism and Mass Communication Quarterly, 74, 515-524.

Rosch, E. H. (1978). Principles of categorization. In E. Rosch \& B. Lloyd (Eds.), Cognition and categorization (pp. 27-48). Hillsdale: Erlbaum.

Rosenberg, E., \& Ekman, P. (Eds.). (1998). What facial expression reveals about emotion, development, psychopathology, and health. New York: Cambridge University Press.

Rusu, A. S., \& Bencic, A. (2007). Choosing a mate in Romania: A cognitive evolutionary psychological investigation of personal advertisements market. Journal of Cognitive and Behavioral Psychotherapies, 7, 27-43.

Saenger, G. (1955). Male and female relations in the American comic strip. Public Opinion Quarterly, 19, 195-205.

Schwab, A. J. (2008). Chi-square test of independence [Lecture notes]. Retrieved from http://www.utexas.edu/courses/schwab/ sw318_spring_2004/SolvingProblems/Class24_ChiSquareTest OfIndependencePostHoc.ppt.

Simmons New Media Study (2009). New media study discovers Americans need 38 hours per day to complete their tasks. Experian Simmons Press Center. Retrieved from http://www. smrb.com/web/guest/press-release-new-media-study-discovery.

Simonton, D. K. (1994). Greatness: Who makes history and why. New York: The Guilford.

Smith, S. L., Pieper, K. M., Granados, A., \& Choueiti, M. (2010). Assessing gender-related portrayals in top-grossing G-rated films. Sex Roles, this issue.

Speed, G. (1893). Do newspapers now give the news? Forum, 15, $705-711$.

Spiegelman, M., Terwilliger, C., \& Fearing, F. (1953). The content of comics: Goals and means to goals of comic strip characters. The Journal of Social Psychology, 37, 189-203.

Stern, B. B. (1999). Gender and multicultural issues in advertising: Stages on the research highway. Journal of Advertising, 28, 1-9.

Stern, S. R. (2004). Expressions of identity online: Prominent features and gender differences in adolescents' World Wide Web home pages. Journal of Broadcasting \& Electronic Media, 48, 218-244.

Street, A. (1909, July 25). The truth about newspapers. Chicago Tribune.

Strinati, D. (2004). An introduction to theories of popular culture. New York: Theatre Arts Books. 
Sussman, N. M., \& Tyson, D. (2000). Sex and power: Gender differences in computer-mediated interactions. Computers in Human Behavior, 16, 381-394.

Tanner, L. R., Haddock, S. A., Zimmerman, T. S., \& Lund, L. K. (2003). Images of couples and families in Disney feature-length animated films. The American Journal of Family Therapy, 31, 355-373.

Titscher, S., Meyer, M., Wodak, R., \& Vetter, E. (2000). Methods of text and discourse analysis. London: Sage.

Trivers, R. L. (1972). Parental investment and sexual selection. In B. Campbell (Ed.), Sexual selection and the descent of man (pp. 136-179). Chicago: Aldine.

Tuchman, G., Daniels, A. K., \& Benet, J. W. (1978). Hearth and home: Images of women in the mass media. Oxford: Oxford University Press.

Welsh, A. (2010). On the perils of living dangerously in the slasher horror film: Gender differences in the association between sexual activity and survival. Sex Roles, this issue.

Welter, B. (1966). The cult of true womanhood: 1800-1860. American Quarterly, 18, 151-174.
Wicks, R. H. (1992). Schema theory and measurement in mass communication research: Theoretical and methodological issues in news processing. Communication Yearbook, 15, 115-145.

Wilcox, D. F. (1900). The American newspaper: A study in social psychology. The Annals of the American Academy of Political and Social Science, 16, 56-92.

Willey, M. M. (1926). The country newspaper: A study of socialization and newspaper content. Chapel Hill: University of North Carolina Press.

Williams, J. E., \& Best, D. L. (1990). Sex and psyche: Gender and self viewed cross-culturally. Newbury Park: Sage.

Woodward, J. L. (1934). Quantitative newspaper analysis as a technique of opinion research. Social Forces, 12, 526-537.

Yule, G. U. (1944). The statistical study of literary vocabulary. Cambridge: Cambridge University Press.

Zhang, Y., Dixon, T. L., \& Conrad, K. (2010). Female body image as a function of themes in rap music videos: A content analysis. Sex Roles, this issue.

Zillmann, D. (1998). Connections between sexuality and aggression (2nd ed.). Hillsdale: Erlbaum. 